\title{
Efficient continuous wave accelerating structure for ion beams
}

\author{
P. N. Ostroumov@, A. S. Plastun, N. Bultman, D. Morris, X. Rao, Q. Zhao, and S. Zhao \\ Facility for Rare Isotope Beams, Michigan State University, East Lansing, Michigan 48824, USA
}

(Received 22 January 2020; accepted 23 March 2020; published 8 April 2020)

\begin{abstract}
The Facility for Rare Isotope Beams driver linac was designed for acceleration of multiplecharge-state beams after the stripping at ion beam energies of 17 to $20 \mathrm{MeV} / \mathrm{u}$ depending on the ion species. The linac includes a $180^{\circ}$ achromatic bend to select multiple charge states for further acceleration and to dump unwanted charge states after the first $45^{\circ}$ magnet. Two of rebunchers between the stripper and the linac segment 2 (LS2) are required to minimize the effective emittance growth of the multiple-charge-state beams and provide matching to the LS2. Recent studies have shown that the best choice for these two rebunchers is a room-temperature (RT) accelerating structure capable of providing robust operation in the presence of the stripped heavy ion beam contaminants. The latter can result in uncontrolled losses of contaminant ions after the passage off the stripper. Therefore, using a superconducting (SC) rebuncher after the stripper is not rational due to possible contamination and performance degradation of SC cavities over a long period of operation. For the beam bunching in the energy range from 13 to $22 \mathrm{MeV} / \mathrm{u}$, two $161 \mathrm{MHz}$ rebunchers based on interdigital H-type (IH) structure were developed, built, installed and commissioned with beam at the FRIB linac. This is the first experimental demonstration for application of a cw RT drift tube accelerating structure in this energy range.
\end{abstract}

DOI: 10.1103/PhysRevAccelBeams.23.042002

\section{INTRODUCTION}

The folding segment 1 (FS1) of the Facility for Rare Isotope Beams (FRIB) linac includes three rebunchers as shown in Fig. 1 [1]. The first rebuncher is required to create a time focus of the beam at the location of the stripper to minimize longitudinal emittance growth due to energy straggling. This rebuncher is located prior to the stripper and requires the highest voltage, which is provided by four quarter-wave superconducting (SC) cavities operating at $80.5 \mathrm{MHz}$. The second rebuncher is necessary to minimize the bunch momentum spread during the transport through the $180^{\circ}$ bend. The third rebuncher provides matching to the following accelerating section linac segment 2 (LS2). These two rebunchers require lower voltage due to increased charge-to-mass ratio, q/A, after the stripper.

As was discussed in our previous publication [2], there was a strong motivation to develop and install a roomtemperature (RT) rebuncher after the stripper due to the concerns of uncontrolled losses of contaminant ions.

Published by the American Physical Society under the terms of the Creative Commons Attribution 4.0 International license. Further distribution of this work must maintain attribution to the author(s) and the published article's title, journal citation, and DOI.

\section{BEAM DYNAMICS REQUIREMENTS IN THE FS1}

The prestripper section of the FRIB linac, the linac segment 1 (LS1), was designed to simultaneously accelerate two charge states of uranium $\left(\mathrm{U}^{33+}\right.$ and $\left.\mathrm{U}^{34+}\right)$ and some lower mass ions in order to meet the beam power requirement of $400 \mathrm{~kW}$ on the target [1]. By design, the LS1 accelerating cavities can be tuned to provide the shortest bunch length of dual-charge-state beam on the stripper to minimize the longitudinal emittance growth. The longitudinal focusing on the stripper is provided by the first SC rebuncher shown in Fig. 1. Due to small longitudinal emittance, the bunch length on the first RT rebuncher downstream of the stripper remains within $\pm 15^{\circ}$ at $80.5 \mathrm{MHz}$. The required voltage of the rebuncher can be reduced by a factor of 2 if the rebuncher is operated at $161 \mathrm{MHz}$. The first RT rebuncher minimizes beam momentum spread to keep the bunch length unchanged up to the second RT rebuncher. The latter provides the longitudinal matching to the LS2. Figures 2 and 3 show the evolution of the longitudinal phase space, rms and full envelopes of five-charge-state uranium beam from the stripper location to the entrance of LS2. To generate these figures, the beam was tracked from the ion source through the radio-frequency quadrupole (RFQ) and LS1 to the stripper. To minimize emittance growth, the rms bunch length at the stripper is below $15 \mathrm{ps}$.

The required effective voltage for the rebunchers was calculated by studying the beam dynamics of all ion species 


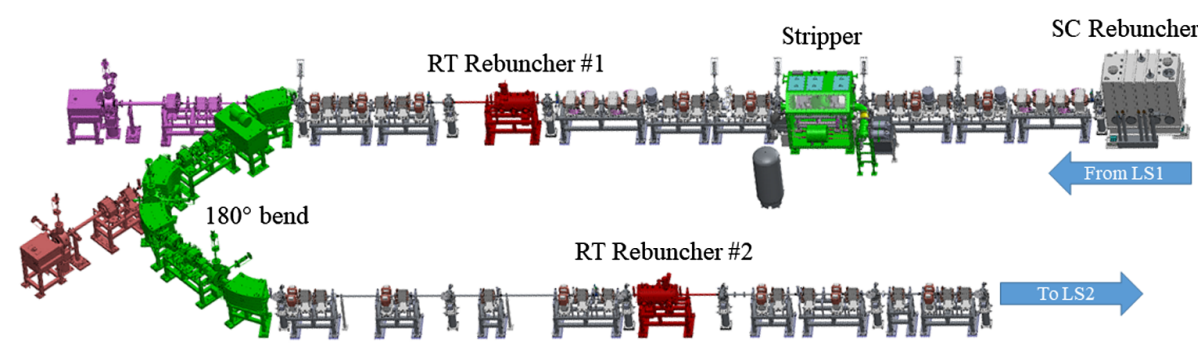

FIG. 1. Layout of the folding segment 1 of the FRIB linac.

from oxygen to uranium including multiple-charge-state heavy ion beams. In addition, the RT rebunchers should be able to provide required functions in the LS1 fault scenarios. The latter means lower beam energy due to the lower available voltage from the LS1 SC cavities. Another fault scenario is low performance of the liquid lithium stripper which can result in lower charge states of ion beam after the stripping. Overall, our studies resulted in the maximum effective voltage of the rebuncher to be equal to $1.0 \mathrm{MV}$ at the nominal beam energy. The nominal energy of the heaviest uranium ions in the FS1 is equal to 16.5 MeV/u, while lighter ions can reach $22 \mathrm{MeV} / \mathrm{u}$. The rebunchers should be able to operate in the energy range of ion species from 13 to $22 \mathrm{MeV} / \mathrm{u}$.
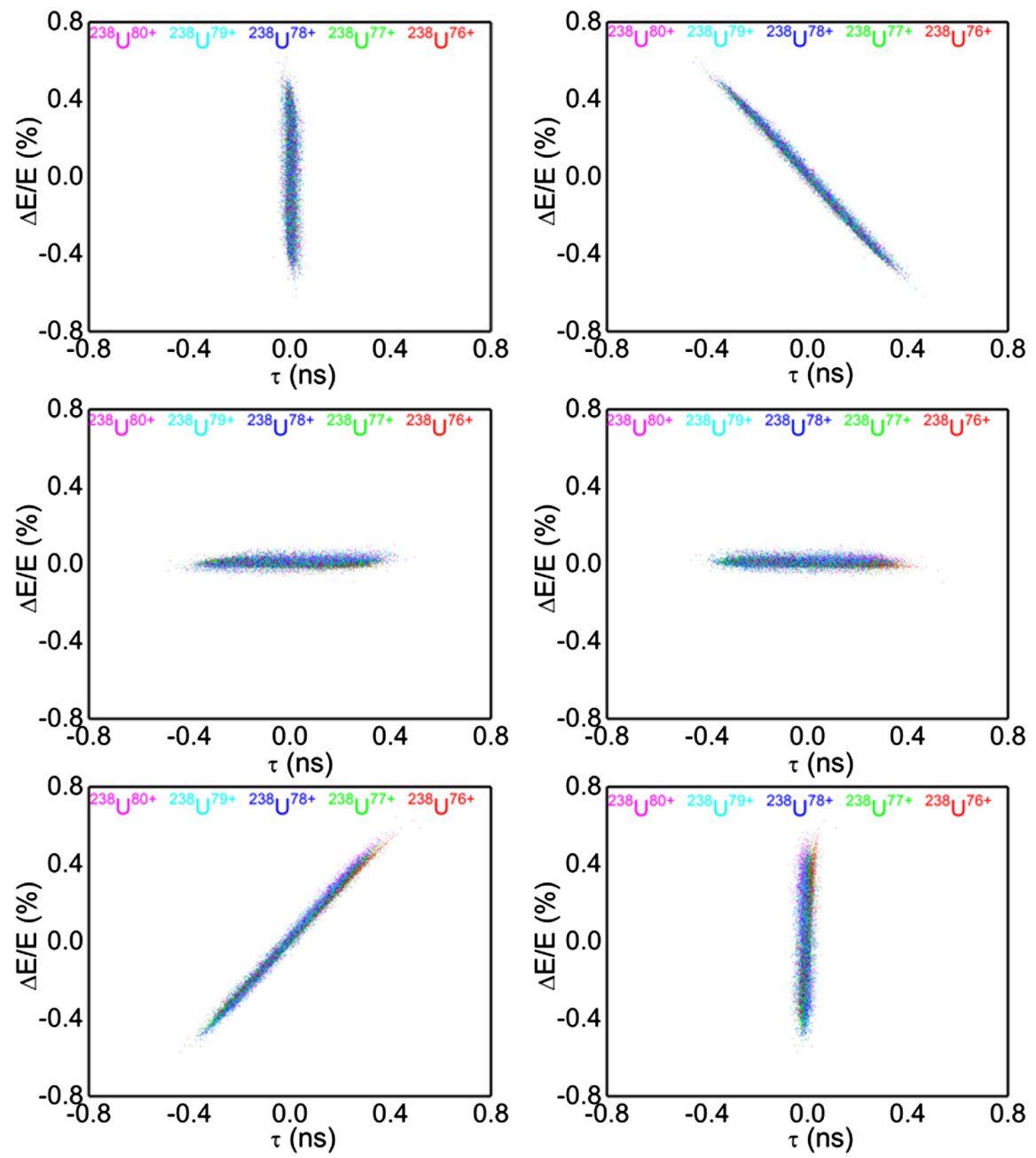

FIG. 2. Multiple-charge-state uranium particle distributions in longitudinal phase space at the stripper exit (top left), at the entrance of rebuncher \#1 (top right), at exit of rebuncher \#1 (middle left), at the entrance of rebuncher \#2 (middle right), at exit of rebuncher \#2 (bottom left) and at the entrance of LS2 (bottom right). 


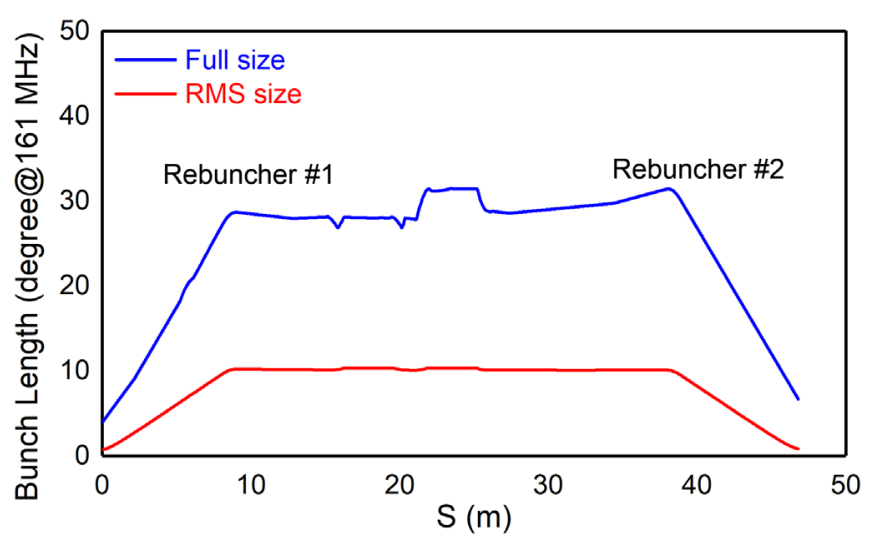

FIG. 3. Bunch length of ${ }^{238} \mathrm{U}$ from the stripper exit through the two rebunchers to the entrance of the LS2.

\section{MULTIPHYSICS DESIGN OF THE ACCELERATING STRUCTURE}

The best candidate for the cw RT structure is an H-type drift-tube resonator [3,4]. Interdigital H-type (IH) structures are known for high shunt impedance, see, e.g., [5,6] and have been used in cw heavy ion linacs at low energies, typically below $1.5 \mathrm{MeV} / \mathrm{u}$ [7]. There are several operational pulsed linacs based on IH structures up to energies of $6 \mathrm{MeV} / \mathrm{u}$. Recently, there were developments to apply IH structures and crossbar H-type $(\mathrm{CH})$ structures for acceleration of protons up to $100 \mathrm{MeV}$ in a pulsed mode [8,9].

In the energy range of $13-22 \mathrm{MeV} / \mathrm{u}$ the H-type structure with drift tubes on round stems appears more efficient than the structure with drift tubes on the vanes [3]. Moreover, this kind of drift tube support is very cost efficient and robust for the mechanical and cooling design. The first step of the resonator design was to optimize the geometry of a single structure cell with the length $L=\beta_{G} \lambda / 2$, where $\beta_{G}=0.185$, corresponding to the nominal velocity of the uranium beam, and $\lambda$ is the wavelength of the buncher's rf field. The drift tube aperture was defined by the beam dynamics. The stem diameter and outer diameter of the drift tube were selected as a compromise between the shunt impedance and cooling design. The gap length is $90 \mathrm{~mm}$ and corresponds to the maximum shunt impedance. Finally, the tank diameter was adjusted to match $161 \mathrm{MHz}$.

The next design step included optimization of the multigap resonator. Due to the H-type mode termination with electrical boundaries (end flanges), the voltage distribution along the resonator is cosinelike [10]. If all $N$ accelerating gaps in the resonator are identical, the field amplitude pattern is also cosinelike, and assuming only the fundamental spatial harmonic of the field can be written as

$$
E_{z}(z)=E_{0} \cos \left(\pi \frac{z}{L}\right) \cos \left(\pi \frac{z}{N L}\right)
$$

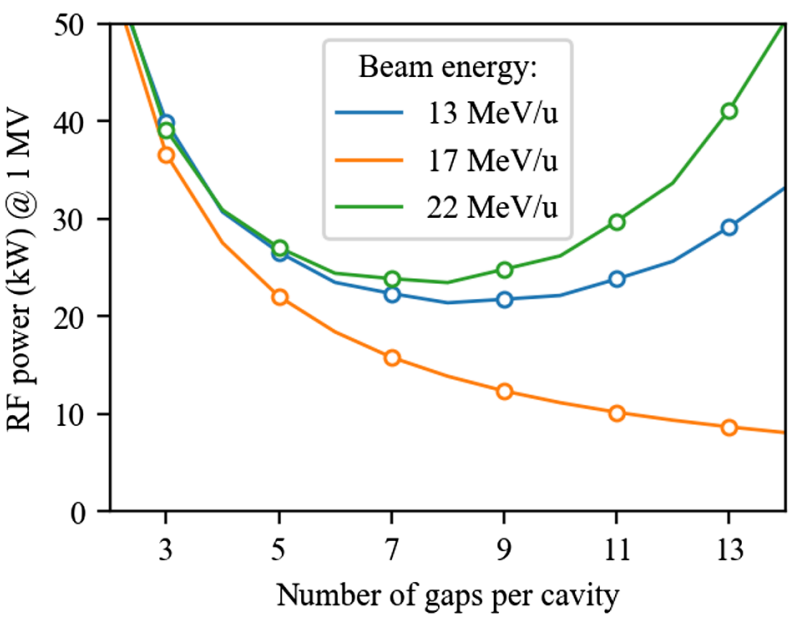

FIG. 4. rf power required to achieve the effective voltage of $1 \mathrm{MV}$ at different beam energies.

where $E_{0}$ is the peak on-axis electric field, and $z$ is the longitudinal coordinate relative to the resonator center. The transit-time factor of the resonator [10] is found as

$$
T(\beta)=\frac{\int_{-N L / 2}^{N L / 2} E_{z}(z) \cos \left(\frac{2 \pi}{\beta \lambda} z\right) d z}{\int_{-N L / 2}^{N L / 2}\left|E_{z}(z)\right| d z} .
$$

Based on simulation results of a single cell and Eqs. (1) and (2), we estimated the rf power required to achieve the effective voltage of $1 \mathrm{MV}$ for 13,17 and $22 \mathrm{MeV} / \mathrm{u}$ versus the number of gaps. On one hand, for the operation with single beam energy, the greater number of gaps per resonator is, obviously, preferable (until the construction cost becomes larger than the savings of rf power). On the other hand, the velocity acceptance of the resonator at 13 and $22 \mathrm{MeV} / \mathrm{u}$ greatly reduces with the number of gaps due to the lack of the synchronism between the field and the beam. Figure 4 shows that the optimum number of gaps for the required energy range is around seven.

The electromagnetic design optimization for the sevengap IH structure was performed using CST STUDIO [11].

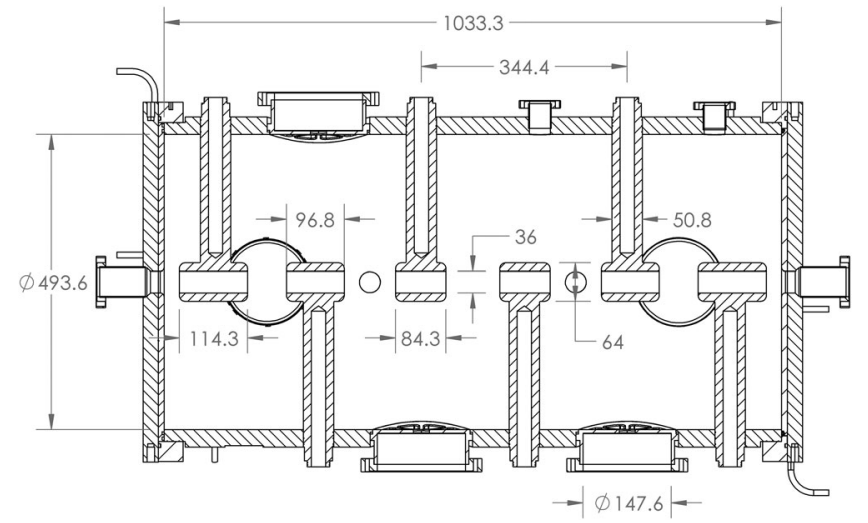

FIG. 5. IH resonator layout. 


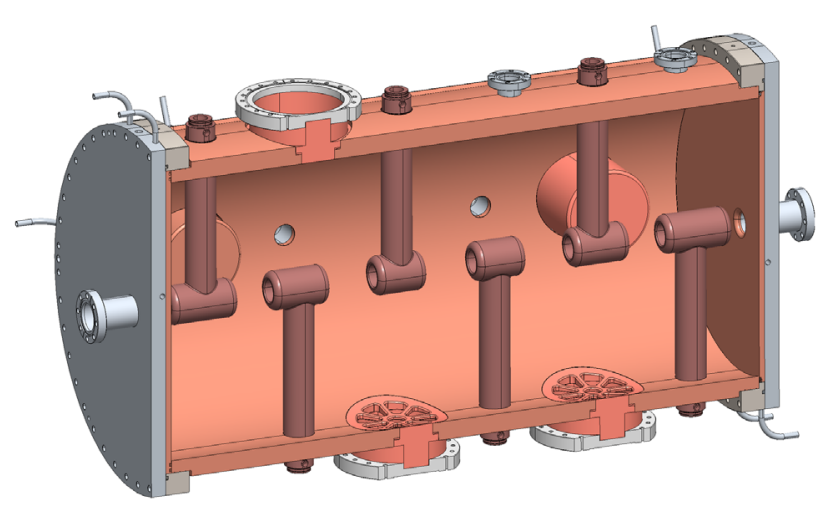

FIG. 6. Cross-section view of the IH resonator assembly.

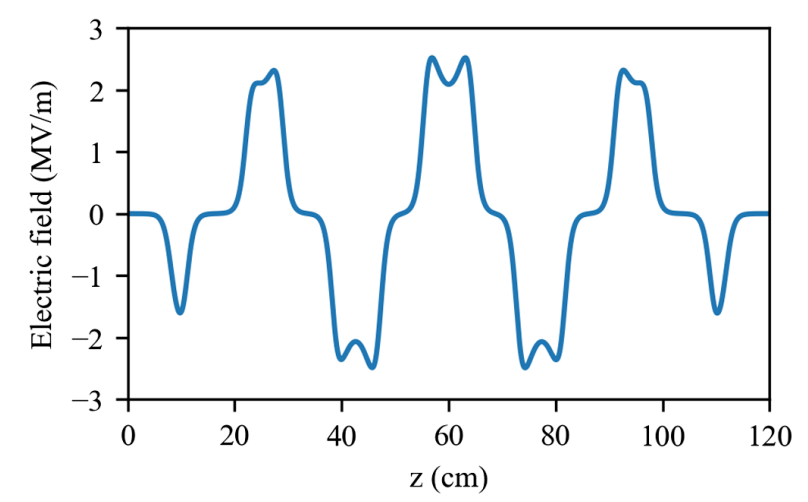

FIG. 7. Accelerating field distribution along the resonator.

The resonator design was iteratively optimized to satisfy vacuum, structural and thermal requirements while maintaining high shunt impedance. The final geometry of the resonator is shown in Figs. 5 and 6. The accelerating field distribution along the resonator axis is shown in Fig. 7. In IH resonators with vanes, the field flatness is improved by means of the undercuts at the vane ends. In a structure with drift tubes on round stems, the field flatness is more difficult to improve. In our design, it has been done by adjusting the gap lengths according to the voltages induced in the gaps.

TABLE I. Main parameters of the rebunchers.

\begin{tabular}{lcc}
\hline \hline Parameter & Units & Value \\
\hline Operating frequency & $\mathrm{MHz}$ & 161.0 \\
Geometrical $\beta_{G}$ & $\ldots$ & 0.185 \\
Aperture diameter, $2 a$ & $\mathrm{~mm}$ & 36 \\
Maximum effective voltage, $V_{\max }$ & $\mathrm{MV}$ & 1.0 \\
Flange-to-flange resonator length, $\mathrm{L}$ & $\mathrm{cm}$ & 115 \\
Intrinsic quality factor & & 15600 \\
Peak electric field at $V_{\max }$ & $\mathrm{Kilpatrick}$ & 0.61 \\
rf power & $\mathrm{kW}$ & 17.5 \\
Shunt impedance & $\mathrm{M} \Omega$ & 57.3 \\
Shunt impedance per unit length & $\mathrm{M} \Omega / \mathrm{m}$ & 50 \\
Energy range & $\mathrm{MeV} / \mathrm{u}$ & $13-22$ \\
\hline \hline
\end{tabular}

${ }^{a}$ Radio-frequency power is calculated to achieve maximum effective voltage for ion velocities equal to $\beta_{G} c$.

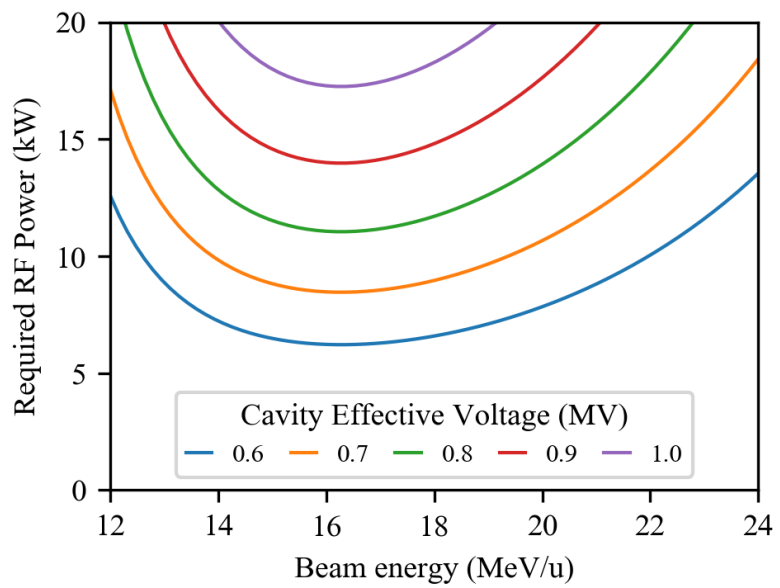

FIG. 8. Required rf power as a function of the ion beam energy.

Table I lists the main parameters of the IH rebunchers after the completion of the multiphysics optimization. Only $0.72-\mathrm{MV}$ effective voltage is required for the rebunching of the uranium beam at a nominal energy of $16.5 \mathrm{MeV} / \mathrm{u}$. This voltage requires $9.1 \mathrm{~kW}$ rf power according to the CST simulations. To provide bunching of the ions entering the rebuncher at nonoptimal velocity, the rf power should be increased to compensate for the lower transit-time factor, as shown in Fig. 8. The rf power of $17.5 \mathrm{~kW}$ is sufficient to provide the required voltages for the ion species in the energy range from 13 to $22 \mathrm{MeV} / \mathrm{u}$.

\section{MECHANICAL DESIGN AND FABRICATION}

The inner diameter of the seven-gap resonator is $\sim 0.5 \mathrm{~m}$ and its length is about $1 \mathrm{~m}$. Therefore, such a resonator can be built from copper material using a high-temperature furnace brazing technique. It is well known that the hightemperature brazing preserves the prebrazing alignment of the components thanks to uniform heating and cooling of the copper and provides nearly theoretical value of the intrinsic quality factor of copper resonators. The assembly view of the resonator is shown in Fig. 9. The body and the drift tubes of the resonator are made of oxygen-free copper. The end plates are made of explosively bonded bimetal composed of stainless steel (SS) and copper. The vacuum sealing of the end plates is provided by Delta metal seals [12] as presented in Fig. 10. The rf sealing is provided by canted coil springs [13].

The resonator body, drift tube stems, end walls, tuners and $\mathrm{rf}$ power coupler are water cooled. The rf power coupler is nearly identical to the coupler previously built for the Argonne National Laboratory RFQ [14]. Drift tubes are cooled via a threaded cooling channel in the stem as shown in Fig. 11. The furnace brazing was applied to copper and SS components. Therefore, the sealing of vacuum space is provided with conflat flanges in all ports and $\mathrm{rf}$ coupler. The fabrication process includes two-step brazing with CuSil alloy. The first step is applied for 


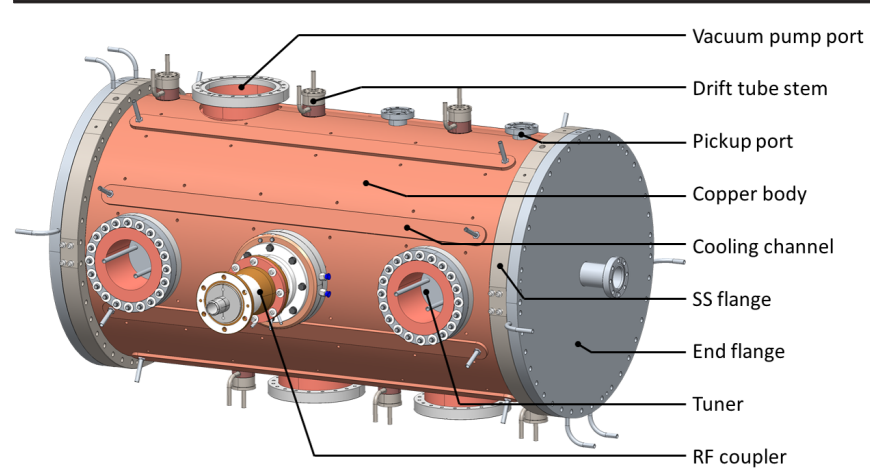

FIG. 9. IH resonator assembly.

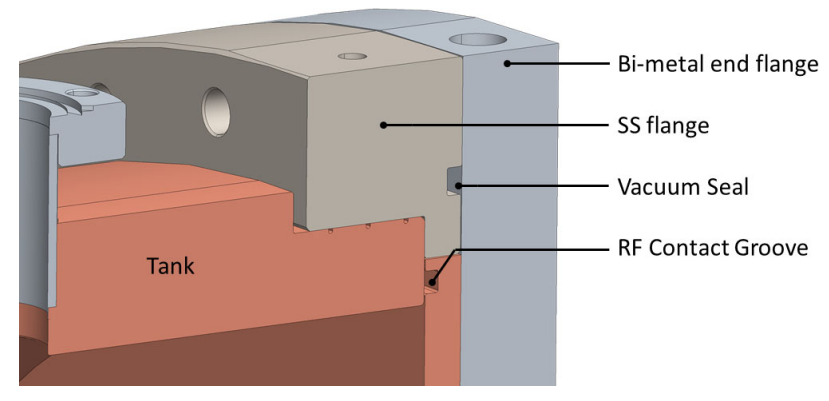

FIG. 10. IH resonator assembly section view with the insert showing the vacuum and rf gaskets.

brazing of cooling channels on the external body of the resonator shown in Fig. 9. The second step is applied for the brazing of all remaining components such as drift tubes, end flanges and ports. For the ports, the SS flanges were prebrazed to copper necks. Due to the proximity of the resonator to the liquid lithium stripper, we completely avoided the water-to-vacuum brazing joints in the design.

The resonator is equipped with three fixed tuners and one motorized tuner. The motorized tuner is in the feedback with a low-level rf system [15] to maintain the resonance during the operation. The $\mathrm{rf}$ contact in the motorized tuner is provided with two rings of silver-plated fingers on the goldplated surface. The cooling water temperature stability is

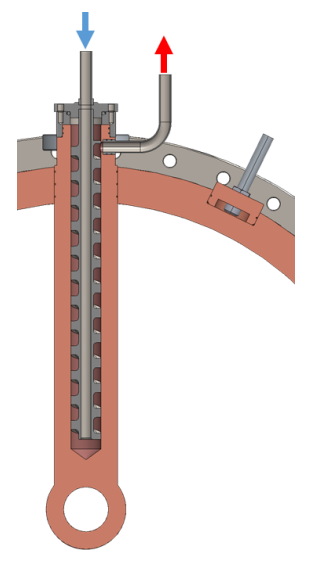

FIG. 11. Design of the drift tube stem's cooling.

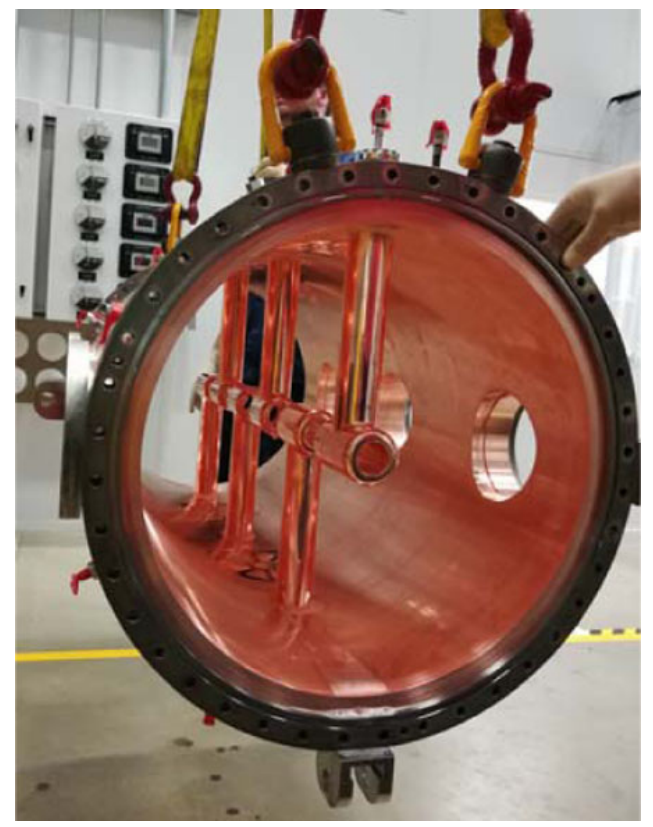

FIG. 12. IH resonator during the final assembly.

maintained within $\pm 1{ }^{\circ} \mathrm{F}$. This stability guarantees that the motorized tuner stroke does not exceed $\pm 0.5 \mathrm{~mm}$ to maintain the resonance and extend the lifetime of the rf springs.

The brazing was performed in the industry [16]. Figure 12 shows the internal view of the brazed resonator during the final assembly.

\section{RF AND BEAM TESTING}

Prior to installation into the beam line, the resonators were vacuum leak checked and rf tuned with a network analyzer. The coupling loop was adjusted for critical coupling, the pickup loops were adjusted for $\sim 50 \mathrm{~dB}$ attenuation and calibrated for measurement of the accelerating field in the resonators. The general view of the first rebuncher installed in its final position in the FRIB tunnel is shown in Fig. 13. The evolution of the rf conditioning process for the first rebuncher is presented in Fig. 14. The first conditioning took less than four hours to reach the stable operation at $1 \times 10^{-7}$ Torr. While the installation of the remaining cryomodules was taking place in the FRIB tunnel, the rebunchers were kept under vacuum with $\mathrm{rf}$ turned off. When we turned on the resonator for the second time after about 8 months, the nominal voltage was reached within 5 minutes as shown in Fig. 14(b). The rebunchers' turn-on time was reduced to $\sim 3$ minutes by now as shown in Fig. 14(c). The second rebuncher exhibited similar behavior. The two vacuum pressure spikes are observed during the transient which possibly corresponds to multipacting but did not cause any vacuum or rf trips due to the reflected power. Currently, both rebunchers are operated at a nominal level of $\mathrm{rf}$ power at a residual gas pressure below $2 \times 10^{-8}$ Torr. So far the accumulated time of cw operation is around 150 hours. 


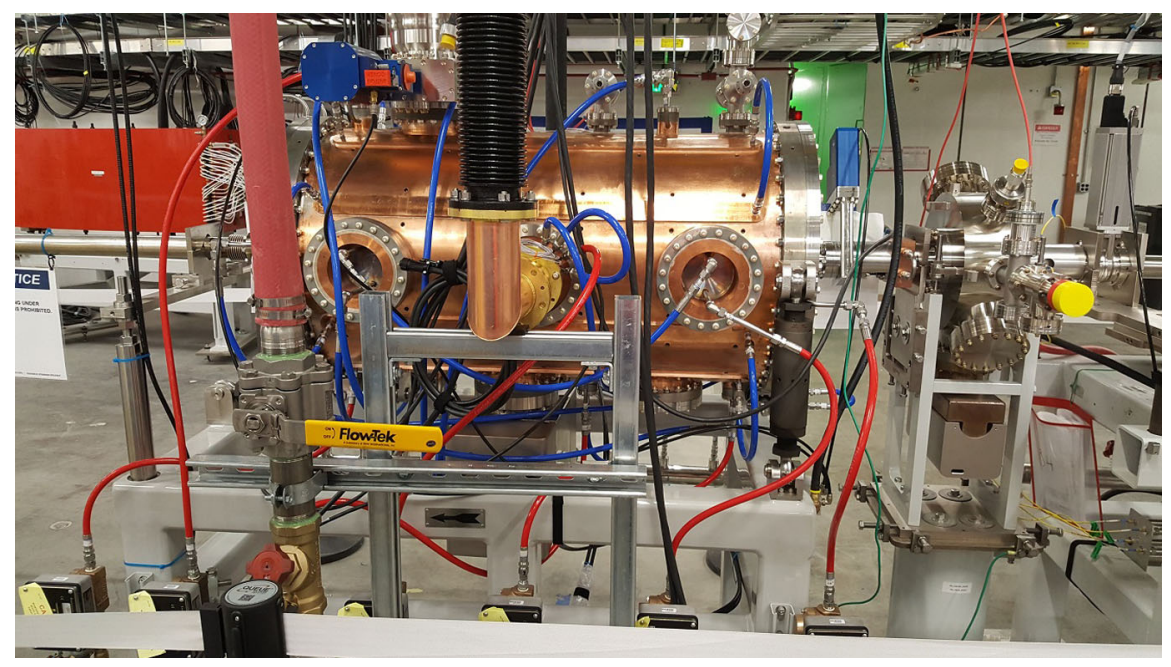

FIG. 13. Rebuncher \#1 installed in the final position in the beam line.

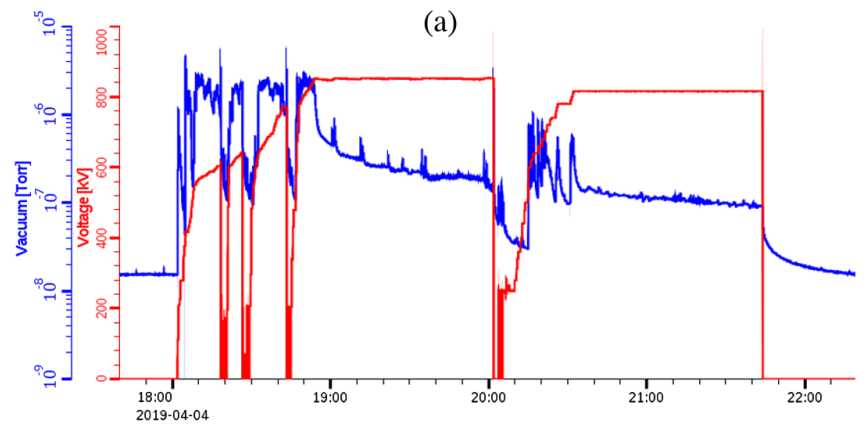

(b)

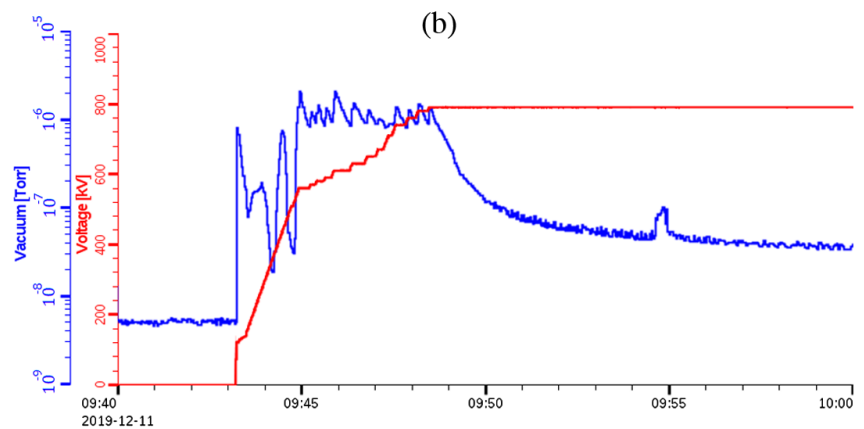

(c)

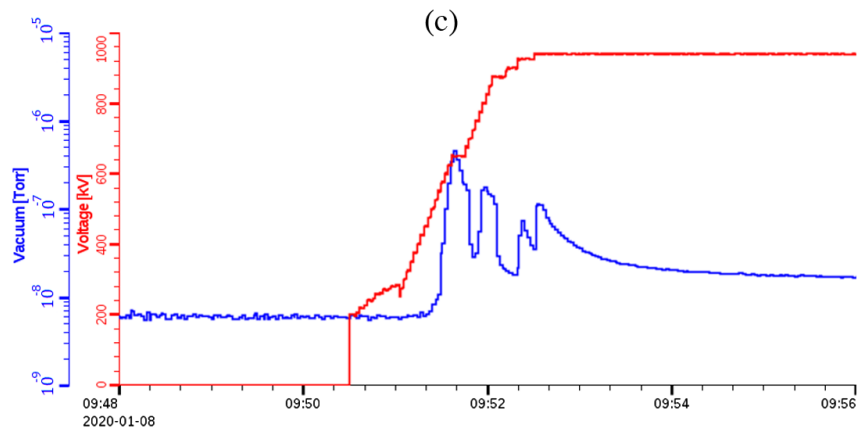

FIG. 14. Residual pressure (blue) and accelerating voltage (red) as a function of time as the resonator turned on for the first (a), second (b) time and recently (c).
The quality factors of the first and second rebuncher, measured at high power by observing the field decay, are $14370 \pm 20$ and $15000 \pm 20$ respectively. The higher $Q_{0}$ of the second rebuncher appears to be due to the surface treatment with a heated Citranox solution in the ultrasonic bath before the final assembly. Both values are close to the simulated quality factor of 15600 .

Beam acceleration was demonstrated by time-offlight beam energy measurements while the rebuncher phase was varied in the $360^{\circ}$ range as shown in Fig. 15. The calibration of the first rebuncher effective voltage with the beam results in $720 \mathrm{kV}$ at $11.2 \mathrm{~kW}$ rf power at optimum velocity which should be compared with $9.8 \mathrm{~kW}$ required from rf measurements. Accordingly, the resonator voltage calibration with beam is consistent with the rf measurements within $5 \%$.

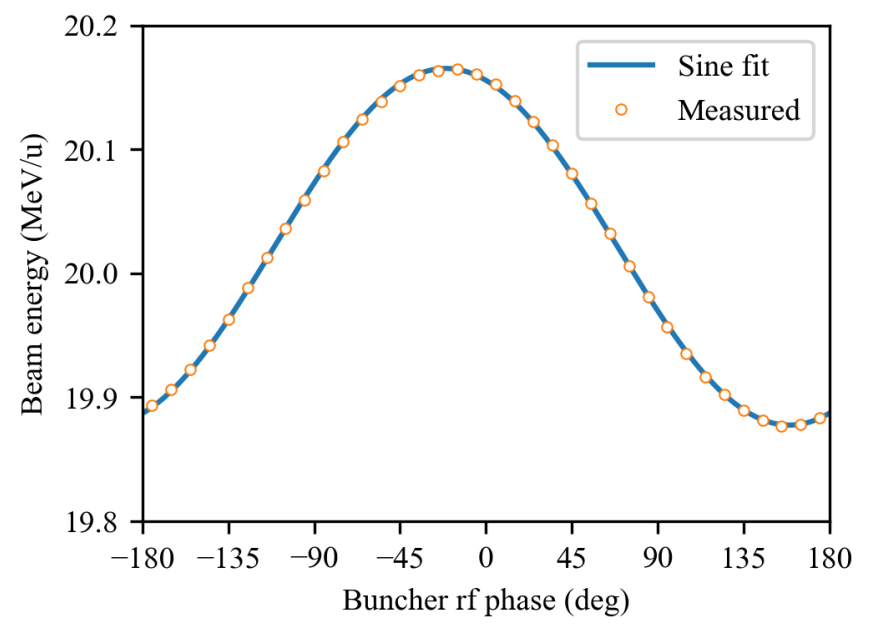

FIG. 15. ${ }^{40} \mathrm{Ar}^{9+}$ beam energy as a function of the rebuncher \#1 phase. 


\section{DISCUSSION}

The fabrication technology developed for H-type resonators resulted in a performance which is nearly identical to the prediction by the CST electromagnetic design code [11]. While the current application requires only $1 \mathrm{MV}$ of accelerating voltage, the proposed structure can be reliably operated at higher voltages and accelerating gradients since the peak surface fields are low. The shunt impedance of $\mathrm{H}-$ type accelerating structures varies roughly as $\beta^{-2}[3,8,10]$ making them especially efficient for low velocities and applicable in lieu of SC structures. In practice, the choice of either H-type room temperature or superconducting structures for acceleration of $\mathrm{cw}$ ion beams below $\sim 20 \mathrm{MeV} / \mathrm{u}$ depends on many aspects specific to a particular research laboratory like available infrastructure, real-estate space and staff expertise, cost of rf system, availability of vendors, etc.

\section{SUMMARY}

A new highly efficient $\mathrm{cw}$ IH-type room-temperature accelerating structure was developed, constructed and commissioned with a beam. The excellent performance of the resonator consistent with the simulations was demonstrated. The successful testing of the resonator with beam opens a new application for $\mathrm{cw}$ room-temperature $\mathrm{H}$ type accelerating structures in the ion beam energies up to $20 \mathrm{MeV} / \mathrm{u}$.

\section{ACKNOWLEDGMENTS}

The authors greatly appreciate the contributions of all FRIB staff to the successful installation and commissioning of the RT rebunchers. The authors also thank their industrial partners from "Kelin" for the excellent job in machining and brazing of copper resonators. This work is supported by the U.S. Department of Energy Office of Science under Cooperative Agreement No. DE-SC0000661, the State of Michigan and Michigan State University.

[1] Q. Zhao, A. Facco, F. Marti, E. Pozdeyev, M. J. Syphers, J. Wei, X. Wu, Y. Yamazaki, and Y. Zhang, FRIB accelerator beam dynamics design and challenges, in Proceedings of the Workshop on High-Intensity and High-Brightness Hadron Beams (HB'12), Beijing, China, 2012, p. 404, https:/accelconf.web.cern.ch/accelconf/HB2012/papers/ weo3b01.pdf.

[2] P. N. Ostroumov, N. Bultman, M. Ikegami, S. Lidia, S. Lund, G. Machicoane, T. Maruta, A. S. Plastun, E. Pozdeyev, X. Rao, J. Wei, J. Wong, T. Xu, T. Yoshimoto, and Q. Zhao, Accelerator physics advances at FRIB, in
Proceedings of the International Particle Accelerator Conference (IPAC'18), p. 2950, http://accelconf.web .cern.ch/AccelConf/ipac2018/papers/thygbf4.pdf.

[3] P. M. Zeidlits and V. A. Yamnitskii, Accelerating systems employing H-type waves, J. Nucl. Energy, Part C 4, 121 (1962).

[4] M. Bres, A. Chabert, F. Foret, D. T. Trant, and G. Voisin, The interdigital H-type (IH) structure, an accelerating structure for low energy beams, Part. Accel. 2, 17 (1971).

[5] U. Ratzinger and R. Tiede, Status of the HIIF RF linac study based on H-mode cavities, Nucl. Instrum. Methods Phys. Res., Sect. A 415, 229 (1998).

[6] U. Ratzinger, The new GSI prestripper linac for high current heavy ion beams, in Proceedings of the 1996 Linear Accelerator Conference, Geneva, Switzerland, p. 288, http://accelconf.web.cern.ch/AccelConf/196/ PAPERS/TU202.PDF.

[7] R. E. Laxdal, G. Dutto, K. Fong, G. Mackenzie, M. Pasini, R. Poirier, and R. Ruegg, Beam commissioning and first operation of the ISAC DTLAT TRIUMF, in Proceedings of the 19th Particle Accelerator Conference, Chicago, IL, 2001 (IEEE, Piscataway, NJ, 2001), pp. 3942-3944, http:// accelconf.web.cern.ch/AccelConf/p01/PAPERS/FPAH112 .PDF.

[8] U. Ratzinger, H. Hähnel, R. Tiede, J. Kaiser, and A. Almomani, Combined zero degree structure beam dynamics and applications, Phys. Rev. Accel. Beams 22, 114801 (2019).

[9] H. Podlech, M. Droba, K. Kümpel, S. Lamprecht, O. Meusel, N. F. Petry, P. P. Schneider, M. Schwarz, J. Baggemann, Th. Brückel, T. Cronert, P.-E. Doege, T. Gutberlet, E. Mauerhofer, U. Rücker, P. Zakalek, S. Böhm, J. Li, and C. Zhang, Conceptual design of the proton linac for the high brilliance neutron source HBS, in Proceedings of the 10th International Particle Accelerator Conference (IPAC'19), Melbourne, Australia, 2019, pp. 910-913, http://accelconf.web.cern.ch/AccelConf/ipac2019/papers/ mopts027.pdf.

[10] P. M. Lapostolle and A. L. Septier, Linear Accelerators (North-Holland Publishing Company, Amsterdam, 1970).

[11] CST Studio Suite, http://www.cst.com.

[12] https://technetics.com/products/sealing-solutions/metalseals/helicoflex-delta/.

[13] https://www.npisprings.com/dynaflex.

[14] P. N. Ostroumov, P. N. B. Mustapha, A. Barcikowski, C. Dickerson, A. A. Kolomiets, S. A. Kondrashev, Y. Luo, D. Paskvan, A. Perry, D. Schrage, S. I. Sharamentov, R. Sommer, W. Toter, and G. Zinkann, Development and beam test of a continuous wave radio frequency quadrupole accelerator, Phys. Rev. Accel. Beams 15, 110101 (2012).

[15] S. Zhao, W. Chang, S. Kim, H. Maniar, D. Morris, P. Ostroumov, J. Popielarski, H. Ren, and N. Usher, The LLRF control design and validation at FRIB, in Proceedings of NAPAC'19, Lansing, MI, 2019, paper WEPLM03 (to be published).

[16] https://www.chnkelin.com. 